\title{
A FILOSOFIA DO DIREITO DE EMIL LASK
}

THE PHILOSOPHY OF LAW OF EMIL LASK

LA FILOSOFÍA DEL DERECHO DE EMIL LASK

José de Resende Júnior²

Resumo: O objetivo do artigo é apresentar e contextualizar a obra Filosofia do Direito de Emil Lask, mostrando suas virtudes e limitações. Inicialmente são apresentadas as circunstâncias em que a obra foi produzida, seguindo-se a exposição das influências teóricas de Lask, com destaque para a filosofia dos valores de Windelband e Rickert. Posteriormente é analisado o modo como Lask aplica a filosofia dos valores ao direito, processo pelo qual a justiça é tomada como o valor fundamental que constitui o significado de todo fenômeno jurídico possível. Por fim, ainda na perspectiva da filosofia dos valores, é examinado o processo de constituição das disciplinas científicas que estudam os fenômenos jurídicos. Palavras-chave: Lask. Filosofia dos valores. Filosofia do direito.

Abstract: The objective of this paper is to present and contextualize the work Philosophy of Law of Emil Lask, showing its virtues and limitations. First of all, it shows the circumstances in which the work was produced, followed by an outlining of Lask's theoretical influences, especially highlighting the philosophy of the values of Windelband and Rickert. We then analyze how Lask applies the philosophy of values to the law, the process by which justice is taken as the fundamental value that constitutes the meaning of any possible legal phenomenon. Finally, still within the perspective of the philosophy of values, this work examines the process of constitution of the scientific disciplines that study the legal phenomena. Keywords: Lask. Philosophy of values. Philosophy of law.

1 Este trabalho é produto das investigações do grupo de pesquisa "Filosofia do Direito (Neo)Kantiana". Todas as traduções apresentadas são de responsabilidade do autor.

2 Professor de filosofia do direito da Universidade Presbiteriana Mackenzie, São Paulo, SP, Brasil. Email: zelotze@gmail.com. 
Resumen: El objetivo del artículo es presentar y contextualizar la obra Filosofía del Derecho de Emil Lask, mostrando sus virtudes y limitaciones. En primer lugar, son presentadas las circunstancias en que la obra fue producida, siguiendo la exposición de las influencias teóricas de Lask, con destaque para la filosofía de los valores de Windelband y Rickert. A continuación, es analizado el modo como Lask aplica la filosofía de los valores al derecho, proceso por el cual la justicia es tomada como el valor fundamental que constituye el significado de todo fenómeno jurídico posible. Por último, aún en la perspectiva de la filosofía de los valores, es examinado el proceso de constitución de las disciplinas científicas que estudian los fenómenos jurídicos. Palabras-clave: Lask. Filosofía de los valores. Filosofía del derecho.

\section{INTRODUÇÃO}

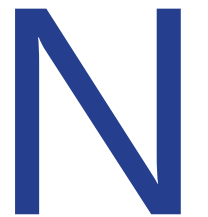
o início do século XX Lask era considerado o prodígio da nova geração da escola neokantiana de Baden, principalmente por causa da sua tese de doutorado intitulada Fichtes Idealismus und die Geschichte, elaborada em Freiburg sob orientação de Rickert e publicada em 1902. ${ }^{3}$

Depois do doutorado, e agora sob orientação de Windelband, Lask vai para Berlin para preparar sua tese de habilitação (Habilitationsschrift), requisito necessário para conseguir um posto de professor de filosofia em qualquer universalidade alemã. Em Berlin, Lask procura se inteirar do debate filosófico sobre o direito, o que resulta na obra Filosofia do direito, que é publicada em 1905 numa obra coletiva em homenagem a Kuno Ficher, sob o título Die Philosophie im Beginn des zwanzigstens Jahrhundersts. Com essa obra, no mesmo ano, Lask consegue sua habilitação na Universidade de Heidelberg como Privatdozent, ou seja, docente autorizado a lecionar, mas sem uma cátedra de ensino ou pesquisa. A partir de fevereiro de 1910, torna-se professor associado e, finalmente, em abril de 1913, professor associado orçamentário e também codiretor dos seminários de filosofia junto com Windelband. ${ }^{4}$

Ao contrário da tese de doutorado sobre Fichte, a Filosofia do Direito de Lask divide as opiniões. György Lukács, por exemplo, a saúda como "revolucionária"

3 GLATZ, Uwe B. Emil Lask: Philosophie im Verhältnis zu Weltanschauung, Leben und Erkenntnis. Würzburg: Königshausen \& Neumann, 2001, p. 13.

4 GLATZ, Uwe B. Emil Lask: Philosophie im Verhältnis zu Weltanschauung, Leben und Erkenntnis. p. 15 
por ter expandido a filosofia dos valores de Windelband e Rickert para o âmbito da historicidade por meio da esfera jurídica. ${ }^{5}$ Gustav Radbruch a considera a influência decisiva para todo o seu trabalho sobre filosofia do direito. ${ }^{6}$ Por outro lado, Rickert, no prefácio às obras completas de Lask, escreve que a Filosofia do Direito é apenas um "trabalho programático".? Já Wolfgang Kersting a considera uma "contribuição pouco profunda e de caráter apenas panorâmico".

A primeira coisa que chama a atenção na leitura da Filosofia do Direito de Lask é o tamanho do texto: apenas 50 páginas. Para os padrões neokantianos e do próprio Lask, isso é muito pouco. Além disso, a impressão que fica da primeira leitura é a de um texto que foi escrito apressadamente, composto em grande parte de notas e observações sobre as obras que o autor estava lendo. O pouco de análise filosófica no texto parece lacunar e quase sempre inconclusiva, o que contrasta fortemente com as rigorosas e precisas análises dos outros trabalhos de Lask.

Pelo que se sabe da produção desse texto, o objetivo inicial de Lask era fazer um trabalho sobre o "espírito objetivo" de Hegel a partir do modelo de análise da filosofia dos valores de Windelband e Rickert, complementado com as inovações sobre o conhecimento histórico introduzidas em sua tese de doutorado. É o que sugere uma carta enviada a Rickert em 20 de março de 1904. Nessa carta, Lask chegou a cogitar o título de Hegels Staatsbegriff para a tese. ${ }^{9}$ Contudo, ao final, o que surgiu não foi um trabalho sobre Hegel, mas apenas um programa para uma filosofia do direito, com apontamentos e tarefas a serem realizadas.

Um motivo que, pelo menos em parte, parece explicar esse caráter inconcluso e programático da Filosofia do Direito diz respeito ao impacto que teve sobre Lask a leitura das Investigações Lógicas (1900/1901) de Husserl. Enquanto

$5 \quad$ LUKÁCS, George. Emil Lask. Ein Nachref. Kant-Studien 22 (1918), p. 351-352.

6 RADBRUCH, Gustav. Rechtsphilosophie. 3. Auflage, Leipzig 1932. (Obras Completas (GRGA), 1988, Band 2, p. 1, nota 1). Em relação à influência de Lask sobre Radbruch veja-se a autobiografia de Radbruch Der innere Weg, Aufriß meines Lebens. In: RADBRUCH, Gustav. Der innere Weg: Aufriß meines Lebens. herausgegeben von Lydia Radbruch, Göttingen 1951, 2. unveränderte Auflage, Göttingen 1961. (Obras Completas (GRGA), 1988, Band 16, p. 217).

7 RICKERT, Heinrich. Geleitwort. In: LASK Emil. Gesammelte Schriften, hg. v. Eugen Herrigel. Bd. 1, Tübingen: J. C. B. Mohr (Paul Siebeck), 1924. p. IX.

8 KERSTING, Wolfgang. Neukantianische Rechtsbegründung: Rechtsbegriff und richtiges Recht bei Cohen, Stammler und Kelsen. In: ders., Politik und Recht: Abhandlungen zur politischen Philosophie der Gegenwart und zur neuzeitlichen Rechtsphilosophie. Weilerswist, 2000, p. 335.

9 apud HOFER, Roger. Gegenstand und Methode: Untersuchungen zur frühen Wissenschaftslehre Emil Lasks. Würzburg: Königshausen und Neumann, 1997, p. 60. 
pesquisava em Berlin, Lask envia uma carta a Rickert, em 5 de agosto de 1903, na qual ele, entusiasticamente, afirma estar lendo o tratado de Husserl, encontrando-se, naquele momento, na primeira metade do segundo volume. ${ }^{10}$ Como se pode observar nos trabalhos posteriores de Lask, especialmente na conferência Gibt es einen "Primat der praktischen Vernunft" in der Logic? (1908) e nos livros Die Logik der Philosophie und die Kategorienlehre (1910) e Die Lehre vom Urteil (1911), o pensamento maduro de Lask se caracteriza por uma profunda reformulação da filosofia dos valores de Windelband e Rickert, o que se deve em boa parte ao diálogo com a fenomenologia husserliana." Isso parece indicar que Lask viveu uma crise teórica durante o processo de produção da Filosofia do Direito. O instrumental teórico da filosofia dos valores com o qual ele planejava tratar do fenômeno do direito já não lhe parecia adequado, mas, ao mesmo tempo, ele ainda não havia elaborado novas ferramentas teóricas, as quais só seriam desenvolvidas na segunda metade da década de dez. Lask não tinha mais tempo para continuar a pesquisa, havia surgido uma vaga de professor em Heidelberg e ele precisava do texto para se candidatar.

Mas apesar desses problemas e limitações, por estranho que pareça, a Filosofia do Direito é a obra de Lask que teve maior influência e repercussão, especialmente no âmbito da filosofia do direito. Além da influência direta sobre Radbruch e Lukács, pode-se citar também a sua repercussão em jusfilósofos como Hermann Heller, Max Ernst Mayer, Wilhelm Sauer, Constantin Tsatsos, Hans Kelsen, Karl Larenz, Hans Welzel e Tércio Sampaio Ferraz. ${ }^{12}$ Além disso, é a obra de Lask que teve mais traduções: japonês em 1921, espanhol em 1946, inglês em 1950, italiano em 1984 e 1989, sérvio em 1991 e português em 2013. ${ }^{13}$

\section{A filosofia dos valores do neokantismo de Baden}

10 apud HOFER, Roger. Gegenstand und Methode: Untersuchungen zur frühen Wissenschaftslehre Emil Lasks. p. 22.

11 Sobre o diálogo e as influências entre a fenomenologia husserliana e a filosofia dos valores de Rickert e Lask veja-se RESENDE JR, José. Em busca de uma teoria do sentido: Windelband, Rickert, Husserl, Lask e Heidegger. São Paulo: Educ/Fapesp, 2013.

12 Sobre a influência de Lask no âmbito da filosofia do direito veja-se SIEGERS, von Josef. Das Recht bei Emil Lask: Untersuchungen zur Rechtstheorie des Neukantianismus. Bonn: H. Bouvier, 1964. p. 2; HOBE, Konrad. Emil Lask Rechtsphilosophie. Archiv für Rechts - und Sozialphilosophie. (59), 1973, p. 221-235; GLATZ, Uwe B. Emil Lask: Philosophie im Verhältnis zu Weltanschauung, Leben und Erkenntnis. p. 15.

13 A tradução para o português foi publicada pela Revista Direito e Práxis, vol. 4, n. 7, 2013, pp. 391-429. 
Para se tratar da filosofia do direito de Lask, é preciso, antes, ter em conta o projeto de filosofia da escola neokantiana de Baden. Fundada por Windelband e desenvolvida por Rickert, mestres de Lask, para essa escola a reflexão filosófica consiste essencialmente numa crítica dos valores. ${ }^{14}$ Mas diferente de uma certa tradição axiológico realista, que remonta a Brentano, passando por Husserl e se consolida com Max Scheler, para o neokantismo os valores não são realidades naturais, psicológicas ou sociais. Valores não têm existência ou efetividade e, a rigor, sequer se pode dizer que "são". Como dirá Lask, valores não são, mas simplesmente valem (gilt). ${ }^{15}$ Essa validade dos valores é o que estrutura o sentido e/ou significado ${ }^{16}$ de todo fenômeno cultural possível, por exemplo, arte, economia, linguagem, direito, religião, arquitetura, ciência, etc. Portanto, para os neokantismos de Baden, o objeto de estudo da filosofia são os valores, que nada mais são do que as condições de possibilidade de constituição do sentido de todo fenômeno cultural possível.

Essa concepção de filosofia como crítica dos valores pretende-se como uma versão da revolução transcendental de Kant. No lugar das formas da intuição e das categorias do entendimento, a investigação é deslocada para a pesquisa dos valores constitutivos de todo tipo de sentido, não só das ciências matemáticas da natureza, como fazia Kant, mas também das ciências humanas, que se desenvolviam no século XIX, e de qualquer outro fenômeno cultural.

Além disso, esse projeto axiológico de filosofia constitui-se como uma resposta à crise de legitimidade pela qual passava a filosofia no final do século XIX. Por meio dele, procurava-se estabelecer um diálogo positivo com as ciências particulares e também garantir um campo de atuação legítimo para a filosofia dentro da pesquisa científica.

Como se sabe, na segunda metade do século XIX, em função da centralidade adquirida pelas ciências, a filosofia foi profundamente desacreditada em relação

14 LASK, Emil. Rechtsphilosophie. Gesammelte Schriften (vol. 1), Hrsg. Eugen Herrigel. Tübigen: J. C. B. Mohr (Paul Siebeck), 1923. p. 287.

15 LASK, Emil. Die Logik der Philosophie und die Kategorienlehre. Gesammelte Schriften (vol. 2), Hrsg. Eugen Herrigel. Tübigen: J. C. B. Mohr (Paul Siebeck), 1923. p. 6.

16 LASK, Emil. Rechtsphilosophie. p. 281. Dependendo do autor neokantiano (Windelband, Rickert ou Lask), a distinção entre sentido e significado (Sinn und Bedeutung) será maior ou menor e desempenhará papel central ou apenas acessório. 
à produção do conhecimento. Por um lado, a filosofia se encontrava fragilizada tanto pela herança especulativa do idealismo alemão quanto pela herança irracionalista do romantismo historicista, o que tornava a maior parte de suas teses sobre a natureza incompatíveis com as descobertas e avanços científicos. Por outro lado, diante do sucesso das ciências particulares, se consolidava dentro das universidades uma ideologia fundada num positivismo cientificista, que em suas variantes materialista, naturalista, vitalista, biologicista, economicista e historicista, colocavam em xeque a legitimidade e a necessidade da filosofia dentro da universidade. Se para o idealismo alemão as ciências particulares eram vistas como engrenagens de um sistema filosófico, a partir da segunda metade do século XIX as ciências particulares se emancipam da filosofia. Nas universidades alemãs as ciências naturais saem do domínio da filosofia e se fundam como faculdades autônomas dando origem, por exemplo, às faculdades de física, química e biologia. Os antigos Institutos Técnicos (Technische Hochschule) se tornam faculdades de tecnologia. Complicando esse quadro, ainda no século XIX surgem as ciências humanas, estruturando as faculdades de ciências políticas, econômicas e sociais, que em sua orientação positivista se viam muito distantes das ciências do espírito (Geistwissenschaft) dos filósofos. Apoiadas em suas revoluções tecnológicas e nos impactos na vida humana, as ciências particulares simplesmente ignoravam as hierarquias propostas pelo idealismo. ${ }^{17} \mathrm{~A}$ universidade se torna, a partir de então, a casa das ciências, o que coloca a filosofia acadêmica contra a parede: se a universidade é o lugar das ciências e toda ciência tem um campo próprio de estudo, do que trata a filosofia? Tem ela um objeto de pesquisa próprio? Produz conhecimento? Qual é a sua função dentro da universidade?

É procurando responder a essas perguntas que se desenvolvem as escolas neokantianas. Visando estabelecer um diálogo produtivo com as ciências, os primeiros pensadores neokantianos encontram na filosofia crítica de Kant princípios a partir dos quais era possível escapar tanto dos exageros especulativos do idealismo alemão quanto fornecer reflexões sobre problemas científicos, dos quais o positivismo cientificista não dava conta, levando sempre ou a alguma

17 SCHNÄDELBACH, Herbert. Philosophy in Germany 1831-1933. Tradução Eric Matthews. Cambridge University Press: Cambridge, 1984, p. 66-108. 
forma de ceticismo ou de metafísica.

A resposta fornecida pelo neokantismo se constituirá, num primeiro momento, como teoria e crítica do conhecimento. A filosofia desempenharia um papel complementar em relação às ciências, esclarecendo metodologicamente o modo de proceder de cada uma delas, delimitando os seus campos de atuação e objetos de pesquisa, e criticando seus pressupostos ideológicos. Essa resposta, entretanto, não significou reduzir a filosofia à epistemologia, como às vezes parecia ser o caso nas primeiras gerações neokantianas. Na escola neokantiana de Baden (Windelband, Rickert e Lask) e depois com Cassirer, a ciência passou a ser vista como um fenômeno cultural ao lado de outros, o que levou a filosofia a ser concebida como crítica dos fenômenos culturais. Em vez de disputar espaço com as ciências na produção do conhecimento, a tarefa da filosofia passa a ser a análise crítica não só da ciência, mas também de outros fenômenos culturais como a arte, a religião, a moral, o direito, a economia, a história, a linguagem e a própria filosofia.

É a partir desse projeto de filosofia como crítica dos valores que Lask procura tratar do fenômeno cultural do direito, o que resultará na obra Filosofia do Direito.

\section{A filosofia dos valores aplicada ao direito}

Lask começa a sua obra traçando um panorama do desenvolvimento da ciência do direito ao longo do século XIX. Se até o início do século XIX todo discurso científico sobre o fenômeno do direito estava intimamente ligado à especulação filosófica, a partir de 1850 a ciência do direito se emancipa da filosofia, fundandose como uma ciência autônoma. Todas as discussões jusfilosóficas anteriores, de Platão a Hegel, passam a ser consideradas pela nova ciência como ultrapassadas e anticientíficas, expressões da "antiga metafísica naturalista do direito". ${ }^{18}$

Essa emancipação da ciência do direito se dá na confluência entre o historicismo e o positivismo, dois movimentos que passam a dominar o pensamento sobre o direito na segunda metade do século XIX.

Por um lado, há as escolas históricas do direito, que oficialmente começam com Friedrich Carl von Savigny, que, influenciado pelo romantismo, rompe com o $18 \quad$ LASK, Emil. Rechtsphilosophie. p. 279. 
racionalismo da Escola Clássica do Direito Natural (Hugo de Grotius, Samuel von Pufendorf, Christian Thomasius, Hobbes, Locke e Kant), criticando sua crença em princípios universais do direito e num parâmetro a-histórico de justiça. O direito passa a ser concebido como parte do espírito do povo (Volksgeist), tendo como principal fonte os costumes e, tal como a língua de um povo, algo que se desenvolve historicamente, de modo mais ou menos independente da vontade dos indivíduos. A noção de justiça também passa a ser considerada como algo histórico que depende da configuração do espírito de cada povo em cada momento histórico.

Por outro lado, desenvolve-se o positivismo, que se tornará a ideologia das ciências particulares e para quem a ciência nada tem a ver com a especulação filosófica, mas com a observação e a análise indutiva de fatos. Para o positivismo jurídico, uma ciência positiva do direito deve, antes de tudo, determinar quais são os fatos observáveis que compõem o fenômeno do direito.

Apesar de serem movimentos inicialmente antagônicos, o que se observa, especialmente no mundo germânico, é uma confluência do historicismo, paulatinamente purificado de seus excessos especulativos, com o positivismo. Essa aproximação do historicismo com o espírito científico do positivismo pode ser observada na evolução das escolas de pensamento jurídico no mundo germânico: depois das disputas entre Savigny e Thibaut sobre o projeto de codificação positivista, percebe-se a influência do positivismo na sucessão das escolas históricas alemãs, começando com a Escola da Jurisprudência dos Conceitos (Begriffsjurisprudenz) do discípulo de Savigny, Georg Friedrich Puchta, passando pela Escola Pandectista (Pandektenwissenschaft) de Bernhard Windscheid, pela Escola da Jurisprudência dos Interesses (Interessenjurisprudenz) de Rudolf von Jhering e até mesmo na crítica materialista de Marx da filosofia do direito de Hegel.

Dessa confluência resultará, segundo Lask, que a ciência do direito terá como lema, no final do século XIX, o "sentido histórico" (historische Sinn). ${ }^{19}$ Essa noção de "sentido histórico" é que estará na base da observação empírica dos fatos estudados pela ciência positiva do direito. Serão considerados fatos jurídicos observáveis, por exemplo, as normas vigentes num determinado tempo e local, os

LASK, Emil. Rechtsphilosophie. p. 278. 
fatos sociais que o direito procura regular e os valores de uma sociedade. Valores aqui entendidos não em sentido neokantiano de condições de possibilidade do sentido/significação, mas no sentido da sociologia, ou seja, como fatores passíveis de observação científica. O que vale tanto no sentido de Max Weber e Talcott Parsons, como fatores de estabilidade ou transformação social, quanto no sentido de Marx, que concebia os valores como epifenômenos das relações de produção econômica de uma sociedade.

Na virada do século XX essa onda positivista levará os novos cientistas do direito, por exemplo, Merkel e Bergbohm, a propor a substituição da filosofia do direito por uma "teoria geral do direito" (allgemeine Rechtslehre).20 Essa disciplina, rigorosamente orientada pelo método indutivo das ciências positivas, não se ocuparia de princípios metafísicos, mas apenas de generalizações a partir da observação de fatos jurídicos. Como exemplos dessas atividades generalizantes Lask cita: a consideração do direito em seus cruzamentos empíricos com outros fenômenos culturais, como a economia, a moral e os costumes; a extração daquilo que seria comum a diferentes situações jurídicas de diferentes épocas e povos; e a determinação dos conceitos mais gerais sob os quais se organizariam as diferentes disciplinas jurídicas particulares. ${ }^{21}$

Assim, para a nova ciência empírica do direito, a especulação filosófica deveria ser substituída por uma disciplina geral do direito, dedicada à catalogação de generalidades extraídas dos fatos jurídicos e elaboradas por indução. Toda investigação sobre um significado (Bedeutung) absoluto do direito e da justiça passa a ser vista como "heresia jusnaturalista" (naturrechtlichen Ketzerei).22

Contra essa pretensão descritiva, Lask denuncia o que se pode chamar de ideologia do fato. Não só para Lask, mas para todo o neokantismo, não existem fatos puros que se oferecem de modo neutro à observação científica. Todo "fato", todo "dado", é sempre já produto de uma construção categorial que depende dos valores que orientam o sujeito em sua observação. Como metaforicamente coloca Lask, "a efetividade empírica e, de modo correspondente, a efetividade da vida histórica" são o palco único sobre o qual atuam os valores constituindo

$20 \quad$ LASK, Emil. Rechtsphilosophie. p. 278.

21 LASK, Emil. Rechtsphilosophie. p. 278-279.

22 LASK, Emil. Rechtsphilosophie. p. 279. 
a realidade (Realität). ${ }^{23}$ Dependendo dos valores que estejam atuando, essa realidade se mostra como natureza, como sociedade, como direito, etc.

O âmbito material que as disciplinas empíricas do direito ingenuamente acreditam apenas descrever em sua consistência fática (faktischen Bestande), em seu desenvolvimento efetivo (tatsächlichen Entwicklung) e em sua relação com outros fenômenos culturais empíricos, deve ser esclarecido, julgado, valorado, examinado em sua legitimidade última, em suma, colocado no contexto de uma concepção de mundo (Weltanschauung). ${ }^{24}$

Em oposição ao ímpeto positivista de substituir a filosofia jurídica por uma Teoria Geral do Direito, Lask se propõe a recuperar a importância da especulação filosófica para o direito, mas sem cair nas construções metafísicas jusnaturalistas. Para tanto, é preciso desenvolver a filosofia jurídica como uma crítica dos valores jurídicos.

Segundo Lask, ao logo da história da filosofia, a validade dos valores sempre foi aquilo que em última instância moveu os filósofos em suas problematizações, não só em relação ao direito, mas também em relação à ciência, à arte, à religião, aos costumes e a qualquer outro fenômeno cultural. O problema é que os filósofos nunca tiveram clareza sobre isso, de modo que o tratamento dos valores sempre foi deturpado. Como os valores não têm existência nem efetividade, mas são a validade que constitui o sentido de todo fenômeno cultural (incluindo o sentido de "existência" e "efetividade"), sempre houve muita dificuldade para se tratar dos mesmos, o que acabou levando a construções metafísicas ou a posições céticas. Toda construção metafísica (desde as cosmologias pré-socráticas até a história do espírito em Hegel) decorre, segundo Lask, de uma hipóstase dos valores. Ou seja, os valores, que apenas constituem o sentido de qualquer objeto possível de nossa experiência cultural, passam a ser considerados como forças, realidades ou entidades autônomas. Por outro lado, toda posição cética e niilista na filosofia decorreria das inconsistências e das desconfianças em relação às construções metafísicas.

Aqui é importante observar que Lask trata o valor a partir de um esquema hilemórfico, algo que aparece apenas de modo embrionário na Filosofia do direito,

24 LASK, Emil. Rechtsphilosophie. p. 280. 
e que só será desenvolvido em profundidade em suas obras de maturidade, ou seja, em Die Logik der Philosophie und die Kategorienlehre (1910) e na Die Lehre vom Urteil (1912). Pensado hilemorficamente, o valor funciona como a forma que envolve o material de nossas vivências. O valor não subsiste em si, mas somente em função de um material. Já o material é simplesmente aquilo que é envolvido pela forma, permanecendo sempre opaco e impenetrável, em vista disso, é definido negativamente com relação à forma como aquilo que não vale, que é estranho ao valor e à significação. Do material em si não se pode dizer nada, pois todo sentido só se constitui como formatação do valor em função da resistência oferecida pelo material. Para Lask, forma e material não são elementos autônomos, mas estruturalmente codependentes. Rigorosamente falando, forma e material são apenas artifícios teóricos para se tratar da relação original (Urverhältnisse) que constitui o objeto em sua significância. ${ }^{25}$

Nesse esquema hilemórfico de Lask, um item fundamental é a sua reflexão sobre a irracionalidade, a qual será desenvolvida mais tarde em sua Die Logik der Philosophie und die Kategorienlehre. ${ }^{26}$ A irracionalidade é a característica fundamental do material. Irracional não é o que está fora e intocado pelas formas lógicas, mas diz respeito à relação funcional do material com a forma lógica, é a opacidade e a impenetrabilidade do material frente à forma categorial. Ou seja, a irracionalidade é intrínseca a toda forma de significação e sentido. Irracional é tudo o que pode ser envolvido pela forma lógica, inclusive a própria forma. Isso mostra que todo sentido se constitui como uma gradação de irracionalidade, pois se trata da determinação da forma em face da opacidade de algum material. Não há sentido na forma pura, mas sim no contato da forma com o material. Esse conceito de irracionalidade deve, por conseguinte, ser distinguido do significado que a palavra irracional tem em seu uso comum na filosofia desde a antiguidade. Se normalmente o irracional é compreendido como aquilo que está fora do logos, como aquilo que não tem nenhuma relação com a forma lógica, para Lask todo material, em sua irracionalidade, mantém uma relação de resistência em face da forma lógica, pois o logos é universalmente englobante e inseparável do material de que é valente. Do ponto de vista de Lask, o que normalmente a filosofia chama $25 \quad$ LASK, Emil. Die Logik der Philosophie und die Kategorienlehre. p. 83.

26 LASK, Emil. Die Logik der Philosophie und die Kategorienlehre. p. 73-80 e 211-222. 
de "irracional" é um material envolvido por formas de valor, mas não esclarecido categorialmente com formas cognitivas, o que mostra que as formas cognitivas são apenas um tipo modificado significação. ${ }^{27}$

A partir desse esquema hilemórfico, Lask observa que toda construção metafísica decorre da não observância da codependência entre o material e a forma, o que leva ao arbitrário hipostasiamento e autonomização do valor.

No caso do direito, essa tendência metafísica é representada pela tradição jusnaturalista, que, segundo Lask, pode ser classificada como formal ou material.

No jusnaturalismo formal algumas significações jurídicas são arrancadas de sua constituição hilemórfica com o material empírico e hipostasiadas em realidades autônomas. O direito natural, então, é concebido como um conjunto de normas ou princípios autônomos em oposição à historicidade do direito empírico. Temse, com isso, duas ordens de significações jurídicas contrapostas: por um lado, o direito ideal e racionalmente transparente; por outro lado, a ordem jurídica real, transitória e limitada em sua opacidade histórica. Em função de sua transparência racional, o direito ideal é visto como hierarquicamente superior, devendo prevalecer sobre a precariedade do direito real, tal qual uma regra constitucional deve prevalecer sobre uma regra infraconstitucional. Uma regra empírica que seja contrária ao princípio ideal é considerada nula, não merecendo ser chamada de direito, mas apenas arbítrio e violência. ${ }^{28}$ Exemplo dessa forma de pensar é o direito natural em Kant, que é fundado na autonomia da razão em oposição ao direito positivo posto pelos Estados.

Já no lado do jusnaturalismo material, o que se tem é a pretensão de esgotar a opacidade histórica do material empírico do direito, tornando-o racionalmente transparente. Em vez de autonomizar certas significações jurídicas, no jusnaturalismo material o que se busca fazer é reduzir todo o material empírico a ideias de validade geral sobre o direito. Com isso, a ordem jurídica real, transitória e limitada do direito é subsumida na transparência racional do direito natural. ${ }^{29} \mathrm{Um}$ exemplo disso é encontrado na filosofia de Hegel, que dissolve a diferença entre

27 Para uma discussão sobre o conceito de irracionalidade veja-se o trabalho RESENDE JR, José. Em busca de uma teoria do sentido: Windelband, Rickert, Husserl, Lask e Heidegger. p. 152-157.

28 LASK, Emil. Rechtsphilosophie. p. 281-282.

29 LASK, Emil. Rechtsphilosophie. p. 283. 
direito natural e direito positivo na dialética histórica de realização do espírito.

Segundo Lask, é mérito do historicismo, encarnado na Escola Histórica do Direito, haver denunciado essas hipóstases jusnaturalistas, tanto formal quanto material, revelando a vacuidade de suas construções especulativas. ${ }^{30}$ É o que se observa na crítica de Savigny que, por influência do romantismo, concebe o Espírito do Povo (Volksgeist) como uma facticidade histórica, opaca e irredutível às formas lógicas do valor. Isso mostra que o conteúdo da realidade histórica do direito é inesgotável em sua riqueza, sendo o erro do jusnaturalismo não respeitar esse "excedente obscuro e insondável da facticidade" das "realidades históricas" do direito. ${ }^{31}$ Mas apesar dessa importante contribuição, Escola Histórica e historicismo flertam perigosamente com o nilismo, pois ao focar apenas na facticidade histórica do direito, negam o valor como sentido incondicionado do direito, sem perceber que, em última instância, é ele que dá sentido para suas construções historicistas.

\section{A justiça como valor}

Do exposto até aqui observa-se que Lask critica tanto as hipóstases jusnaturalistas do valor quanto os perigos niilistas do historicismo e do positivismo. Como resume o filósofo, "O direito natural e o historicismo são os dois precipícios com os quais a filosofia do direito deve tomar cuidado." ${ }^{32}$

Na sequência dessas críticas, Lask fornece algumas indicações do que seria um caminho consistente para a pesquisa jusfilosófica. Uma filosofia do direito consistente deve se ocupar do valor do direito, o que implica a pesquisa de um significado absoluto e incondicionado do direito, mas sem cair em alguma forma de jusnaturalismo. Como se verá, trata-se de uma via de investigação que pretende coordenar aspectos dos procedimentos da pesquisa histórico positivista com a pretensão de validade do jusnaturalismo.

Segundo Lask, na ideia de "justiça" tem-se a significação mais geral do valor do direito. ${ }^{33}$ Tal como a "verdade" para a ciência, a "justiça" é a expressão do valor 
fundamental do direito. A princípio essa afirmação parece óbvia, o problema, entretanto, é que não é possível estabelecer uma definição única e definitiva de justiça. Qualquer tentativa nessa direção implica hipostasiar o valor e cair na arbitrariedade das construções jusnaturalistas. Como se viu, o puro valor não subsiste em si, mas sempre em relação a um material. O significado dos fenômenos jurídicos se constitui na singularização do valor em face da facticidade histórica da realidade social, em cada época e sociedade, constituindo as "concepções de mundo" (Weltanschauung). ${ }^{34}$ Como escreve Lask, é

\footnotetext{
... inútil procurar uma definição única de justiça. Dado que com este termo quer-se simplesmente expressar a absolutidade e aprioridade do direito enquanto tal, nele seria preciso reunir todos os requisitos de como seria o direito em cada uma das diferentes concepções de mundo. ${ }^{35}$
}

Como é impossível tratar diretamente do valor do direito, Lask propõe comparar as concepções de mundo como forma de aproximação desse valor, ou seja, trata-se de analisar como se constituem e se definem as noções de justiça nas concepções de mundo ao longo da história. Contudo, essa análise implica apenas uma aproximação assintótica do valor do direito, pois o valor não se dá em si, mas apenas indiretamente nas configurações do significado da justiça.

Um bom meio para comparar a noção de justiça em concepções de mundo diferentes é por meio da análise das especulações jusfilosóficas produzidas dentro de cada concepção de mundo. Segundo Lask, na época em que escrevia o trabalho, havia duas concepções de mundo principais que orientavam o pensamento sobre uma significação absoluta do direito.

Por um lado, uma concepção de mundo individualista, própria do iluminismo e que tem a sua maior expressão teórica em Kant. Para essa concepção de mundo o valor do direito é pensado a partir da realização ética dos indivíduos, ou seja, a partir da liberdade individual. O direito e as instituições sociais por ele reguladas são justos se servem para proteger e coordenar a autonomia dos indivíduos. ${ }^{36}$ O direito como estrutura de uso legítimo da força seria apenas um mecanismo 
externo às personalidades individuais, criado instrumentalmente com a função de equacionar os conflitos de modo a proteger a autonomia dos indivíduos da melhor forma possível. ${ }^{37}$ Logo, o valor do direito não seria um valor específico, mas se fundaria em valores éticos individuais, normalmente expressos na ideia do "bem". Com isso, o direito seria acessório à ética e toda investigação científica deveria estar articulada com essa. Como exemplo contemporâneo dessa forma de pensar, Lask cita Die Lehre von dem richtigen Rechte (1902) de Rudolf Stammler. ${ }^{38}$

Por outro lado, em oposição à anterior, desenvolve-se no século XIX uma concepção de mundo social, alternativa ao relativismo do positivismo e do historicismo, e que tem a sua maior expressão teórica em Hegel. Segundo Lask, em Hegel o valor do direito é concebido não a partir do indivíduo, mas das instituições sociais. Ajustiça seria expressão de um valor social, e não meramente pessoal, como no kantismo. Não se trata de negar o valor pessoal, mas de perceber que a personalidade individual, capaz de se realizar eticamente, só se desenvolve em sociedade. Pretende-se, assim, uma subsunção entre o valor individual e o valor social, o que em Hegel é descrito por meio da história do espírito, que se realiza dialeticamente como espírito subjetivo (pessoa), espírito objetivo (sociedade) e espírito absoluto. ${ }^{39}$ Além de Hegel, essa concepção social do valor do direito podia ser observada em pensadores como Fichte, Schelling, Schleiermacher, Stahl, Trendelenburg, Krause, Schuppe, Jellinek, Lasson, Largade, Tönnies, Cohen, Lassalle, Rotbertus, Jhering. ${ }^{40}$

Para Lask, essas duas concepções de mundo determinavam as discussões mais apuradas sobre o valor do direito no início do século $X X$ europeu:

Toda a filosofia do século dezenove se esforça para afirmar um sentido absoluto próprio das relações sociais, sem ter que renunciar com isso ao reconhecimento do indivíduo como absoluto fim em si mesmo, conquistado no século dezoito. Até o presente a luta dessas concepções de mundo não deram nenhum passo na direção de sua solução. ${ }^{41}$

37 LASK, Emil. Rechtsphilosophie. p. 297.

38 LASK, Emil. Rechtsphilosophie. p. 293.

39 LASK, Emil. Rechtsphilosophie. p. 300.

40 LASK, Emil. Rechtsphilosophie. p. 295-306.

41 LASK, Emil. Rechtsphilosophie. p. 293. 
Mas apesar do estágio da discussão, permanecia em aberto a questão de saber se o valor do direito poderia ser reduzido aos valores pessoais da ética, se o valor do direito seria socialmente autônomo, ou se haveria alguma possibilidade de conciliar as duas posições.

\section{A ciência do direito}

Na segunda parte do trabalho, Lask trata especificamente do valor da ciência do direito, o que, segundo ele, nada mais é do que uma investigação sobre a metodologia das disciplinas científicas que se ocupam do fenômeno do direito.42 Não se trata mais do valor do direito, a justiça, mas sim do valor da ciência, a verdade. Enquanto no direito o valor de justiça é aquilo que está pressuposto na constituição do significado de todo fenômeno jurídico, na ciência aplicada ao direito o valor de verdade é aquilo que está pressuposto na constituição de todo significado científico sobre fenômenos jurídicos. Trata-se, portanto, de uma investigação sobre a produção do conhecimento nas disciplinas especializadas do direito.

A primeira parte dessa metodologia da ciência do direito é a investigação do processo de formação dos conceitos jurídicos. Tomando a teoria da formação dos conceitos de Rickert, elaborada em Die Grenzen der naturwissenschaftlichen Begriffsbildung (1896), Lask procura mostra que, tal como acontece com outros fenômenos culturais, também no direito existem duas dimensões de formação dos conceitos: uma pré-científica e outra científica. ${ }^{43}$

Por meio da linguagem, especialmente das funções de "nomes próprios" e "nomes genéricos", tem-se uma formação pré-científica de conceitos, a qual promove uma redução de complexidade da realidade fático histórica do direito. Esses conceitos não são forjados de modo lógico e sistemático, mas organicamente, em função dos contextos culturais que ancoram as línguas. Ainda não é um "trabalho" de cientistas, mas um produto espontâneo do uso cotidiano da língua que fazem as pessoas de uma determinada comunidade.

Posteriormente, partido de construções conceituais pré-científicas, cientistas

$42 \quad$ LASK, Emil. Rechtsphilosophie. p. 306-329.

43 LASK, Emil. Rechtsphilosophie. p. 307-308. 
constroem conceitos científicos, os quais são forjados logicamente em função de interesses generalizantes ou individualizantes. ${ }^{44}$ Essas construções também procuram reduzir a complexidade da realidade fático histórica do direito, mas agora por meio de uma sistematização lógica.

Lask observa que na maior parte dos conceitos jurídicos não há uma separação clara entre os processos pré-científicos e científicos de formação de conceitos. O que se observa, normalmente, é uma evolução gradativa no processo de formação dos conceitos, que começa de modo pré-científico e depois é corrigido e adaptado cientificamente. Como exemplo dessa correção científica dos conceitos pré-científicos, Lask cita a discussão sobre o conceito de personalidade jurídica e a proposta de Georg Jellinek de substituir a imprecisa oposição entre "pessoa física" e "pessoa jurídica", que mistura elementos naturalistas e jurídicos, pela oposição entre "pessoas jurídica individual" e "pessoa jurídica coletiva". ${ }^{45}$

A partir da análise do processo de formação dos conceitos, Lask observa que, no estágio de desenvolvimento da ciência do direito no início do século XX, essa se dividia em "jurisprudência" e "teoria social do direito".

Na jurisprudência, o direito é visto como um complexo de significações e o que se investiga é a sistematicidade desses conceitos. Trata-se da investigação das significações das normas em seu "conteúdo dogmático" e dos conceitos jurídicos de modo geral, por exemplo, dolo, dolo eventual, culpa, culpa consciente; negligência, imperícia, imprudência; responsabilidade subjetiva e responsabilidade objetiva; fato jurídico, ato jurídico, negócio jurídico. ${ }^{46}$

Já na teoria social do direito esse é visto como um fator cultural real, como um processo da vida social. ${ }^{77}$ Nesse caso, o cientista, seja um sociólogo ou um historiador, distingue e relaciona o direito com outras manifestações da vida social, como costumes, religião, economia, etc. ${ }^{48}$ Segundo Lask, esse tipo de abordagem científica se desenvolveu na segunda metade do século XIX, podendo ser observado na crítica marxista do direito, tendo como um de seus maiores

$44 \quad$ LASK, Emil. Rechtsphilosophie. p. 307.

45 LASK, Emil. Rechtsphilosophie. p. 322-323.

46 LASK, Emil. Rechtsphilosophie. p. 301-302.

47 LASK, Emil. Rechtsphilosophie. p. 311.

48 LASK, Emil. Rechtsphilosophie. p. 313. 
expoentes Karl Renner, e na evolução dos escritos de Jhering. ${ }^{49}$

Por fim, observa-se que essa análise dos ramos da metodologia científica do direito não é exaustiva, de modo que é possível o desenvolvimento de novas disciplinas e também a obliteração daquelas existentes.

\section{CONSIDERAÇÕES FINAIS}

Como se procurou mostrar, a Filosofia do Direito de Emil Lask é uma obra produzida em condições adversas: no meio de uma crise teórica, com prazo exíguo e com as necessidades profissionais da vida acadêmica batendo à porta. Tais condições contribuíram para uma obra lacunar, de caráter muito mais programático do que analítico, e que muito destoa das outras obras do filósofo.

Apesar disso, é uma obra que vale a pena ser estudada, especialmente pelo modo original como a justiça é problematizada como o valor constitutivo do significado dos fenômenos do direito, e, de modo complementar, agora considerando o valor "verdade", como se estruturam metodologicamente as disciplinas científicas que se ocupam dos fenômenos jurídicos.

\section{REFERÊNCIAS DAS FONTES CITADAS}

GLATZ, Uwe B. Emil Lask: Philosophie im Verhältnis zu Weltanschauung, Leben und Erkenntnis. Würzburg: Königshausen \& Neumann, 2001.

HOBE, Konrad. Emil Lask Rechtsphilosophie. Archiv für Rechts - und Sozialphilosophie. (59), 1973, p. 221-235.

HOFER, Roger. Gegenstand und Methode: Untersuchungen zur frühen Wissenschaftslehre Emil Lasks. Würzburg: Königshausen und Neumann, 1997.

KERSTING, Wolfgang. Neukantianische Rechtsbegründung: Rechtsbegriff und richtiges Recht bei Cohen, Stammler und Kelsen. In: ders., Politik und Recht: Abhandlungen zur politischen Philosophie der Gegenwart und zur neuzeitlichen Rechtsphilosophie. Weilerswist, 2000. p. 334-339.

LASK, Emil. Fichtes Idealismus und die Geschichte. Gesammelte Schriften (vol. 1), Hrsg. 49 LASK, Emil. Rechtsphilosophie. p. 313-314. 
Eugen Herrigel. Tübigen: J. C. B. Mohr (Paul Siebeck), 1923. p. 1-274.

Rechtsphilosophie. Gesammelte Schriften (vol. 1), Hrsg. Eugen Herrigel. Tübigen: J. C. B. Mohr (Paul Siebeck), 1923. p. 275-331. (Filosofia do Direito. Tradução José Resende. Direito e Práxis. Vol. 4, n. 7, 2013. p. 391-429.)

Gibt es einen "Primat der praktischen Vernunft" in der Logic? Gesammelte Schriften (vol. 1), Hrsg. Eugen Herrigel. Tübigen: J. C. B. Mohr (Paul Siebeck), 1923. p. 247-356.

Die Logik der Philosophie und die Kategorienlehre. Gesammelte Schriften (vol. 2), Hrsg. Eugen Herrigel. Tübigen: J. C. B. Mohr (Paul Siebeck), 1923. p. 1-283.

Die Lehre vom Urteil. Gesammelte Schriften (vol. 2), Hrsg. Eugen Herrigel. Tübigen: J. C. B. Mohr (Paul Siebeck), 1923. p. 284-457.

LUKÁCS, George. Emil Lask. Ein Nachref. Kant-Studien 22 (1918). p. 349-370.

RADBRUCH, Gustav. Rechtsphilosophie. 3. Auflage, Leipzig 1932. (Obras Completas (GRGA), 1988, Band 2, p. 206-450).

Der innere Weg: Aufriß meines Lebens. herausgegeben von Lydia Radbruch, Göttingen 1951, 2. unveränderte Auflage, Göttingen 1961. (Obras Completas (GRGA), 1988, Band 16, p. 167-297).

RESENDE JR, José. Em busca de uma teoria do sentido: Windelband, Rickert, Husserl, Lask e Heidegger. São Paulo: Educ/Fapesp, 2013.

RICKERT, Heinrich. Geleitwort. In: LASK Emil. Gesammelte Schriften, hg. v. Eugen Herrigel. Bd. 1, Tübingen: J. C. B. Mohr (Paul Siebeck), 1924.

Die Grenzen der naturwissenschaftlichen Begriffsbildung: eine logische Einleitung in die historischen Wissenschaften. Freiburg: J. C. B. Mohr, 1896.

SCHNÄDELBACH, Herbert. Philosophy in Germany 1831-1933. Tradução Eric Matthews. Cambridge University Press: Cambridge, 1984.

SIEGERS, von Josef. Das Recht bei Emil Lask: Untersuchungen zur Rechtstheorie des Neukantianismus. Bonn: H. Bouvier, 1964.

STAMMLER, Rudolf. Die Lehre von dem richtigen Rechte. Berlin: J. Guttentag, 1902. Recebido em: abril/2016 Aprovado em: julho/2017 